\title{
Nano Particles and Nano Composites for Preservation of Historic Marble Minbars with Application on the Minber of Soliman Pasha Al-Khadim Mosque in Salah El-Din Citadel in Cairo, Egypt
}

\author{
Mohamed Abd El Hady, Sayed Hemada* (i), Mahmoud Algohary \\ Conservation Department, Faculty of Archaeology, Cairo University, Giza, Egypt \\ Email: *sayed.hemeda@cu.edu.eg
}

How to cite this paper: El Hady, M.A., Hemada, S. and Algohary, M. (2019) Nano Particles and Nano Composites for Preservation of Historic Marble Minbars with Application on the Minber of Soliman Pasha Al-Khadim Mosque in Salah El-Din Citadel in Cairo, Egypt. Open Journal of Geology, 9, 957-973.

https://doi.org/10.4236/ojg.2019.913099

Received: November 24, 2019

Accepted: December 16, 2019

Published: December 19, 2019

Copyright $\odot 2019$ by author(s) and Scientific Research Publishing Inc. This work is licensed under the Creative Commons Attribution International License (CC BY 4.0).

http://creativecommons.org/licenses/by/4.0/

\begin{abstract}
Minbar, in Islam, the pulpit from which the sermon (khutbah) is delivered. In its simplest form, the minbar is a platform with three steps. Often it is constructed as a domed box at the top of a staircase and is reached through a doorway that can be closed. Soliman pasha Al-Khadim mosque in Salah El-Din citadel in Cairo is considered the first mosque with ottoman architectural style. This Minbar exposed to aggressive human intervention by mosque workers and archaeological crafts unity-ministry of antiquities in Egypt, to lose more of its historical and architectural values. Now this Minbar undergoes restoration process, they are removing all modern pigments and remains of last reconstruction in 2014 so we proposed some Nano particles and Nano composites for Preservation of it. The study started with the characteristics of the historic architectural elements of Mibars and their joining structural mortars in order to risk assessment and to define the necessary characteristics of the intervention retrofitting new materials, which will be used in the ongoing preservation work of these stucco architectural elements. To achieve such, several analyses and laboratory tests like ultra-sonic pulse method testing and uniaxial compression test were carried out to determine their basic, physical and mechanical properties, along with the microstructural properties determination using Mercury porosimeter. On the other hand, the morphological description, petrography, mineralogical and microstructural properties were determined using scanning electron microscope equipped by EDS, transmission electron microscopy TEM, polarizing light microscopy, XRD and XRF. The results proved the superiority of the samples that have been
\end{abstract}


strengthened by nano lime concentration of $2 \%$ with Wacker $\mathrm{OH} 100$ concentration in $5 \%$.

\section{Keywords}

Historic Marble, Minbar, Nano-Lime, Nano Titanium, Nano Composites, Salah Al-Din Citadel, Preservation

\section{Introduction}

Historical stone and marble minbars in Islamic mosque architecture all over the Islamic world are very rare so it's very important to preserve them. In Egypt, there are eight stone minbars only from Mamluk, Ottoman and Mohamed Ali family era, also, there are remains of Fatimid minbar Al-Khotary in Islamic art museum in Cairo. All stone Minbars are exposed to aggressive environmental and geo-environmental factors, especially stone Minbar which carved and extracted from bad sedimentary rocks. In other side, marble minbars resist many deterioration factors but have been affected by human deterioration factors aggressively like failure conservation interventions, explosion and other deterioration factors like groundwater, air pollution and differential soil settlement.

One of the most important minbars is the minbar of Soliman pasha Al-khadem in citadel of Salah El-Din in Cairo, Egyptas shown in Figure 1. The Mosque of Soliman Pasha is considered to be the first Ottoman-style mosque in Egypt. The new mosque was the result of a complete renovation and restoration program on the site of the old mosque built in AH 535/AD 1140 by Abu Mansur Qastah Ghulam Al-Muzaffar Ibn Amir Al-Juyush, who was the Governor of Alexandria during the Fatimid period. This minbar is considered to be the oldest marble minbar in Cairo in the Ottoman era, and is engraved on the sides such as the Turkish marble minbars [1].

This minbar dated back to the construction time of the mosque; the pulpit was constructed in a building style (see Figure 2). The dimensions of this minbar are (length 3.50 - width 0.88 - height 5.07). It was built on a separate base extending from $2 \mathrm{~m}$ to $1.75 \mathrm{~m}$. The inner body of the minbar was built of limestone blocks. The seat of the Khateeb was linked to the eastern-south wall of the western-south Iwan. This minbar from white marble and decorated with painted and carved star patterns, Turkish writtens and hatti flowers paints.

This minbar was exposed to reconstruction processes more than one time. In 2014, by the department of Archaeological Crafts of the Ministry of Antiquities. This pulpit suffered from many human damages caused by the acts of vandalism and explosion that occurred on citadel, the mosque in the early twentieth century and all the facilities located in the citadel of Salah El-Din Al-Ayyubi, as well as the effect of the irrigation water from the gardens surrounding the mosque. Geologists see that the existence of the mosque on a part of Mokattam 

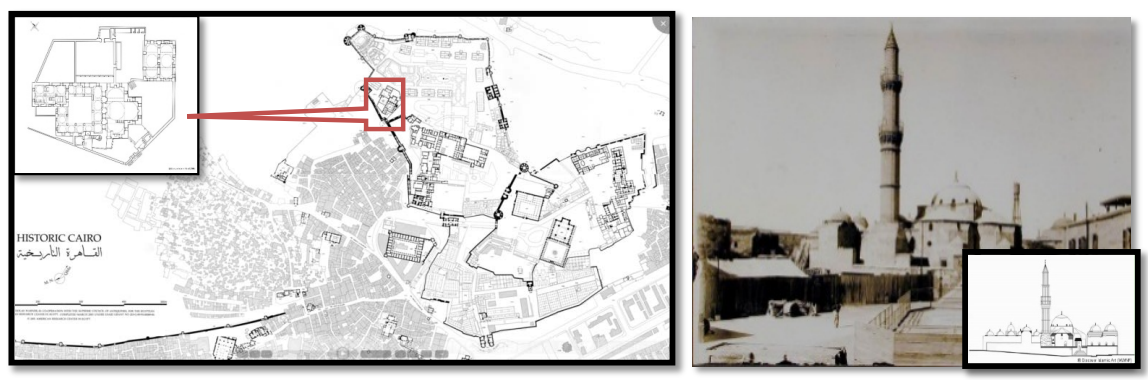

Figure 1. Location map and layout of mosque of Soliman pasha al-khadim in Salah El-Din Citadel, Cairo, Egypt (After Warner, 2005).

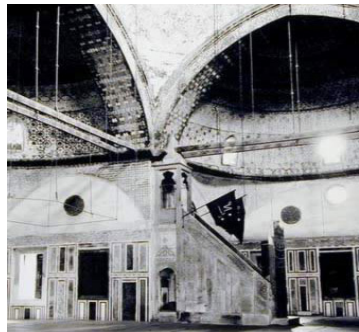

(a)

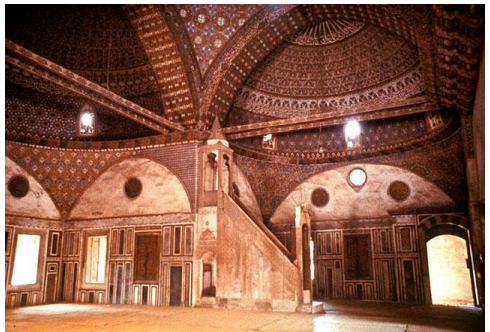

(b)

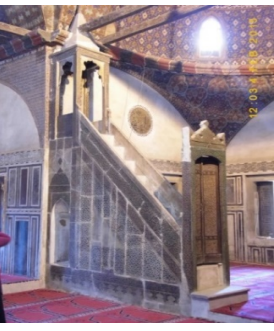

(c)

Figure 2. Old photos of Minbar through times (a) minbar photo in 1929; (b) minbar in 1998; (c) minbar now after reconstruction.

Formations with the containment of child metals in the geological formation is strongly influenced by the presence of water in various forms and sources. Unfortunately, the pulpit was exposed during the last decade to dismantle and re-install by the department of Archaeological Crafts of the Ministry of Antiquities.

The most damage caused by human factors as wrong conservation intervention that happened by unity of archaeological crafts-ministry of archaeology (without any scientific plan introduced with conservators and engineers' team), this minbar exposed to destructive reconstruction and need to be detached and reconstructed again and aggressive problem (see Figure 3). Exactly the environmental condition has affected on this minbar that appears in high relative humidity and variation of temperature degrees. The gardens around the mosque and damaged irrigation systems caused rising of groundwater table which have impact on the structure of the mosque and the minbar inside.

Recently, nanomaterials and various synthetic nanocomposites have been widely used in consolidation and protection of archaeological stone artworks.

Paraloid B 72 is an acrylic co-polymer formed by ethyl methacrylate (70\%) and methyl acrylate) (30\%) provides a good combination of rigidity, resistance and adhesion, but it has also some drawbacks, as the treated surfaces become yellow because of its oxidation by UV radiation and its water repellence decreases over time [2] [3].

Organosilans have been commonly used since the 1960s [4] and have been a popular consolidation choice, particularly in Europe [5]. The British Museum 

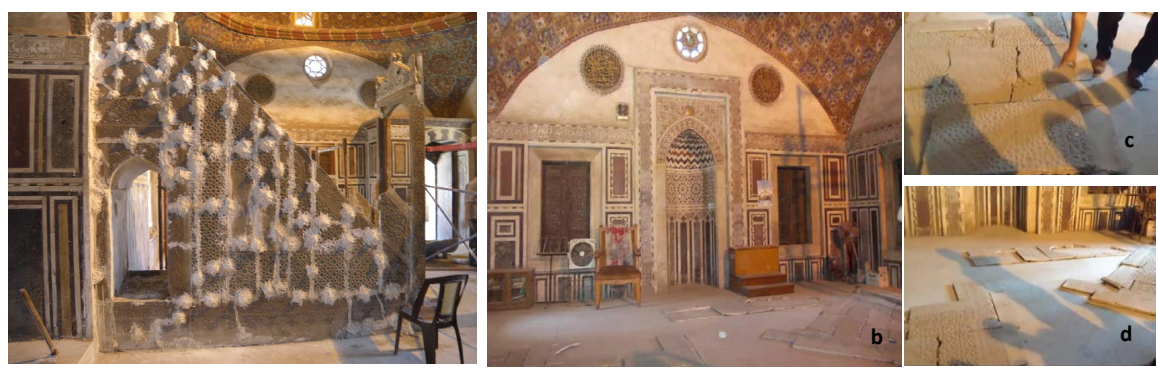

Figure 3. The minbar through the reconstruction processes by technicians of archaeological workshops unity of archaeology ministry in 2104. (a) the patches of gypsum mortar for fixing slabs and the inner construction; (b) the aggressive storing of marble slabs of minbar and how amount of dusts and uncontrolled environmental conditions as shown in (c), (d).

started to use them in the 1980s, but to a lesser extent than the continent's institutions, and for several years it has not used them. Only consolidants based on silicone are used to enhance internal cohesion [6] [7].

Nano $\mathrm{TiO}_{2}$ mixed with polymer commonly used to improve and enhance historical materials, improve also their mechanical properties and be super water repellent and self-cleaning [8]. $\mathrm{TiO}_{2}$ has the ability to show high transparency and photocatalytic activity by cleaning up organohalides found in groundwater and environmentally friendly [9] [10].

Nano silica and nano titanium improved its efficiency in the consolidation and strengthening of the historic bricks in aggressive marine environment also these nanomaterials were very effective in the preparation of the restoration mortars [11] [12].

\section{Concept and Construction Techniques of Minbars}

Well understanding of the design and construction technique of the minbar is initial phase before its intervention retrofitting. Its size must be compatible with the area of Iwan AlQebla and has a ratio between over components which divided into two sections:

- RUNWAY (ALMADRAG) [staircase-two sides-door handrail].

- CASTEL (DJAWSAQ) [dome-stands-Cornish-door of rawda].

Golden ratio is very important to have stable and compatible minbar [13]. The golden mean proportion is a proportional system whereby two elements are related to each other by a set proportion. Two segments of a line not equal to each other are related in a proportion: $\mathrm{a} / \mathrm{b}=(\mathrm{a}+\mathrm{b}) / \mathrm{a}$ (Figure 4$)$. It is this unique point that divides the single line into segments with qualitative proportions [14].

Especially for stone minbar, it must be stood on stable isolated footing and the behind wall must be prepared to force the load of this sample structure as mentioned and displayed in Figure 5.

In the Islamic world, most minbars are made of wood because it is a light material, making the minbar easy to move around and are highly decorated. There 


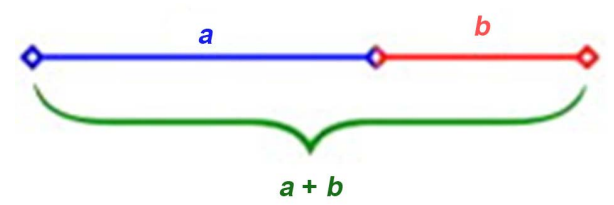

Figure 4. Equation of golden ratio (Afrer Dabbour, 2012).

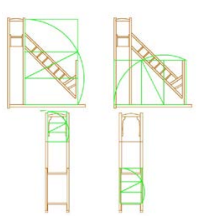

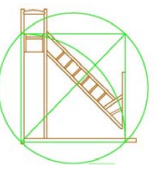

(a)

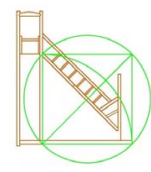

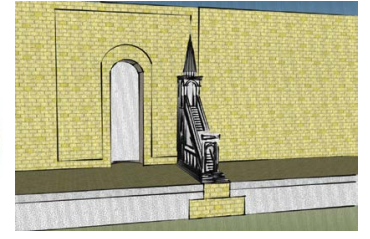

(b)

Figure 5. (a) Proportion of minbar components and golden ratio in designing of minbar (Bozorgmehr, 2009) and (b) The isolated footing under stone minbar (researcher work).

are other minbars (plural. manabir) that have been built with various materials such as marble, stone, even iron during Umayyad era.

In Ottoman era, although most minbars were made of wood some of the most important were built of marble. Thus, in the Selimiye Cami in Edirne there is a tall minbar of Marmara marble which is widely regarded as the finest in Turkey. The form of this minbar with its solid portal, its steep stairs and tall hood are all characteristic Ottoman features [15].

\section{Materials and Methodology}

\subsection{Examination and Analytical Devices}

\subsubsection{Digital Light Microscope}

Optical (or light) microscopes are used to magnify small objects and can provide information about the structure and characteristics of a sample [16].

\subsubsection{Stereomicroscope}

Stereo microscopes provide lower magnification than compound microscopes. Stereo microscope magnification typically ranges from $5 \times-80 \times$ and the images seen are three-dimensional images rather than a flat image. A stereo microscope may also be referred to as a dissecting microscope.

\subsubsection{Polarizing Microscope}

All samples examined in the laboratory uses Germany Orthoplan 110780 Labphot2-pol, Olympus BX40 and Olympus BHSP trinocular petrographic microscope that is equipped with digital cameras, $35-\mathrm{mm}$ cameras, fluorescent attachments, and image analysis software for examinations and photo micrographic documentations at various mode [17] [18] [19] [20].

Scanning electron microscope coupled with EDX device

S E M Model Quanta 250 FEG (Field Emission Gun) Attached with E D X 
Unit(EDX) Energy Dispersive X-ray Spectroscopy, with accelerating voltage 30 K. V., Magnification $14 \times$ up to $1,000,000$ and resolution for Gun. In). K550X Sputter Coater, England.

\subsubsection{Transmission Electron Microscope (TEM)}

The JEM-2100 is a multipurpose, $200 \mathrm{kV}$ analytical electron microscope. Multipurpose $200 \mathrm{kV}$ TEM with simple and ease-of-use operability and excellent expandability Excellent LaB6 electron gun promises excellent performance with a reasonable cost. Ultrahigh TEM resolution as high as $0.19 \mathrm{~nm}$ (in UHR configuration) enables us to perform an observation at atomic resolution. EDS (Energy Dispersive X-ray Spectrometer) with a $0.28 \mathrm{sr}$ of solid angle (in HR configuration with a $50 \mathrm{~mm}^{2}$ detector) performs highly sensitive analysis at nanometer resolution. Highly stable specimen stage enables us to perform a long-term observation and analysis.

\subsubsection{X-Ray Diffraction}

A Philips X-Ray Diffraction equipment model PW/1710 with Monochromator, Cu-radiation (1.542 $\AA$ ) at $40 \mathrm{~K} . \mathrm{V} ., 35$ M.A. and scanning speed $0.02 \mathrm{o} / \mathrm{sec}$. were used. The reflection peaks between $2 \theta=2 \mathrm{o}$ and $60 \mathrm{o}$, corresponding spacing $(\mathrm{d}$, $\AA$ ) and relative intensities (I/Io) were obtained. The diffraction charts and relative intensities are obtained and compared with ICDD files.

\subsubsection{X-Ray Florescence}

A Philips X-ray Fluorescence equipment, model Philips PW/1404, with RH target and six analyzing crystal for determining major and trace elements, The concentration of the analyzed elements were determined by using software Kernl $\mathrm{X}-44$, The maximum power for the equipment $3 \mathrm{Kwt}$. The samples were prepared by fusion bead machine perlx 2 presser for pressed pellets.

\section{Petrography Study of Marble Minbars}

Twelve Marble samples collected from minbar of Soliman pasha AL Khadim have been analyzed and examined with mentioned analytical methods and devices to identify the mineral composition and microstructure of the marble under investigation in addition to the characterization of the degradation and disintegration patterns. The broad analytical study revealed that the construction material of the minbar is white Carrara marble (see Figure 6). The marble thin section examinations under stereo microscope explain the substrate formation and its thickness (12 um:37 um). The marble cross thin section examinations under the polarizing light microscopy show calcite $\mathrm{CaCo} 3$ and dolomite $\mathrm{Ca} \mathrm{Mg}$ $\left(\mathrm{Co}_{3}\right)_{2}$ the main and principal minerals in the mineral composition of this marble, the exfoliation of sample structure is obvious. The examination of the marble samples under the Scanning Electron Microscopy SEM shows the crystals of salts in particular the Halite $\mathrm{Na}$ Clinside and on sample surface. The micro analysis via the energy dispersive X-ray EDX technique shows the quantitative elemental composition of the investigated marble sample, the main elements are 


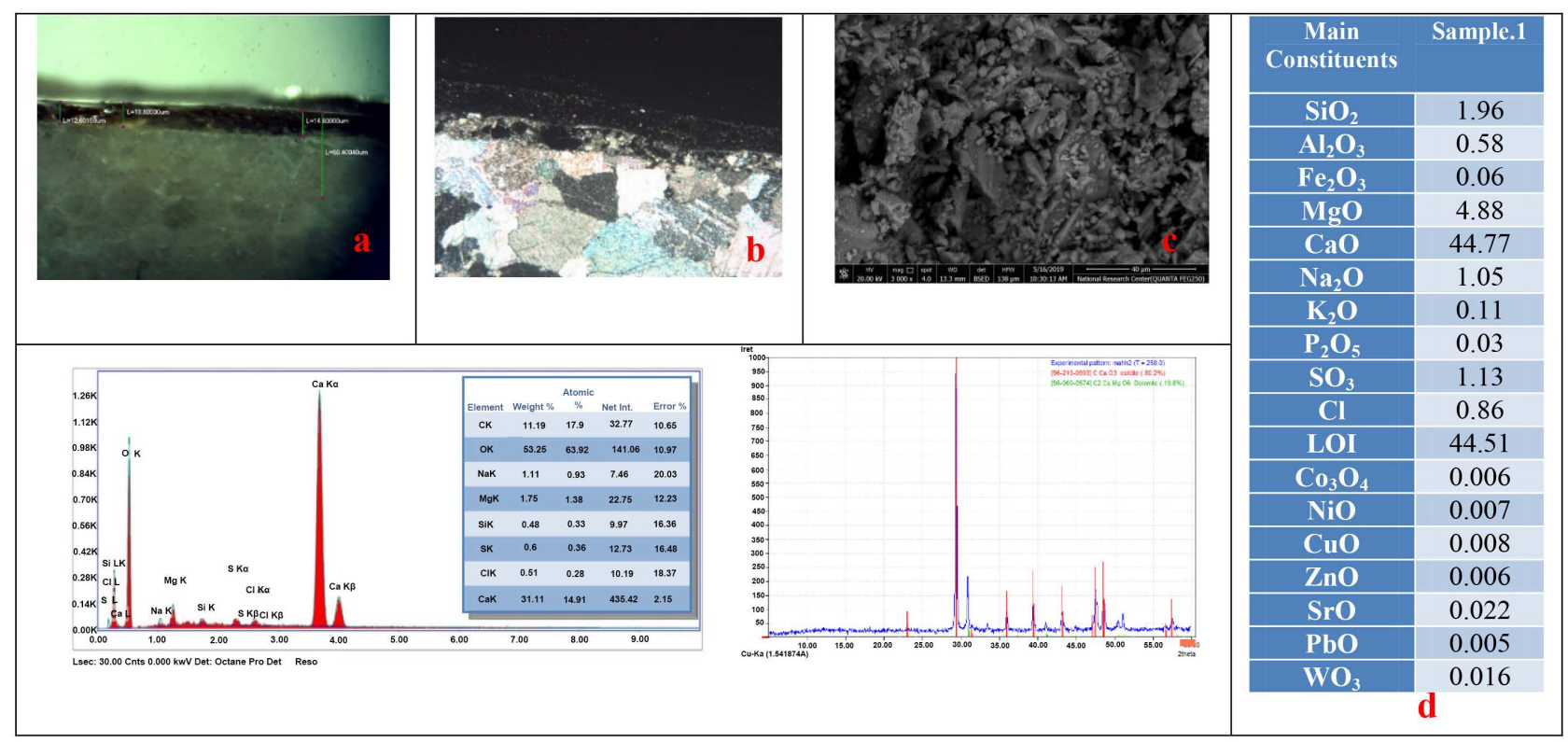

Figure 6. Cross-thin section under stereo microscope explain substrate formation and its thickness (12 um:37 um) (a), (b) cross thin section graph of marble samples shows calcite and dolomite as principal minerals and exfoliation of sample structure, (c) micrograph of SEM of salts crystalline on sample surface, (d) EDX technique shows the elemental composition of the investigated marble sample. 1 by EDX, such as $\mathrm{Ca}, \mathrm{Mg}, \mathrm{C}, \mathrm{O}$ and $\mathrm{Si}$, (c) XRD showed the main composites (calcite (80.2\%) and dolomite $(19.8 \%)$ and $(d)$ showed the results of XRF affirmed the previous results and the marble type is carrara marble.

$\mathrm{Ca}, \mathrm{Mg}, \mathrm{C}, \mathrm{O}$ and $\mathrm{Si}$. The X-ray diffraction analysis $\mathrm{XRD}$ showed that the main compound of the samples is calcite $\mathrm{CaCo}_{3}(80.2 \%)$ and dolomite $\mathrm{Ca} \mathrm{Mg}\left(\mathrm{Co}_{3}\right)_{2}$ (19.8\%). The quantitative micro analysis via the X-ray Florescence XRF confirmed the previous analytical results and the marble type is Carrara marble, the main elements and its percentage are presented in Figure 6(d).

\section{The Experimental Study}

\subsection{Marble Samples Preparation and Nano Composites (Consolidants)}

We have collected 36 cubic weathered and disintegrated marble specimens coming from an old masonry and naturally aged and have the same mineral composition and statue of preservation of our historical marble samples of minbar. All specimens prepared approximately in $(3 \mathrm{~cm} \times 3 \mathrm{~cm} \times 3 \mathrm{~cm})$ and divided into 12 groups each group have code name and composed of three specimens as shown in Figure 7 (a). Then dried in electric oven for 24 hours at $100+/-5^{\circ} \mathrm{C}$.

The consolidation and protective materials have been used is Paraloid B 72 is an acrylic co-polymer formed by ethyl methacrylate (70\%) and methyl acrylate) (30\%). It provides a good combination of rigidity, resistance and adhesion. The other stone strengthener and protective is the SILRES ${ }^{\circ} \mathrm{BS} \mathrm{OH}$ is a solventless ethyl-silicate manufactured by Wacker Chemie AG, it is commonly used as water-repellent/consolidants material [21] [22]. Consolidation materials and nanocomposite materials and their percentage used in our experimental study are summarized in Table 1. 

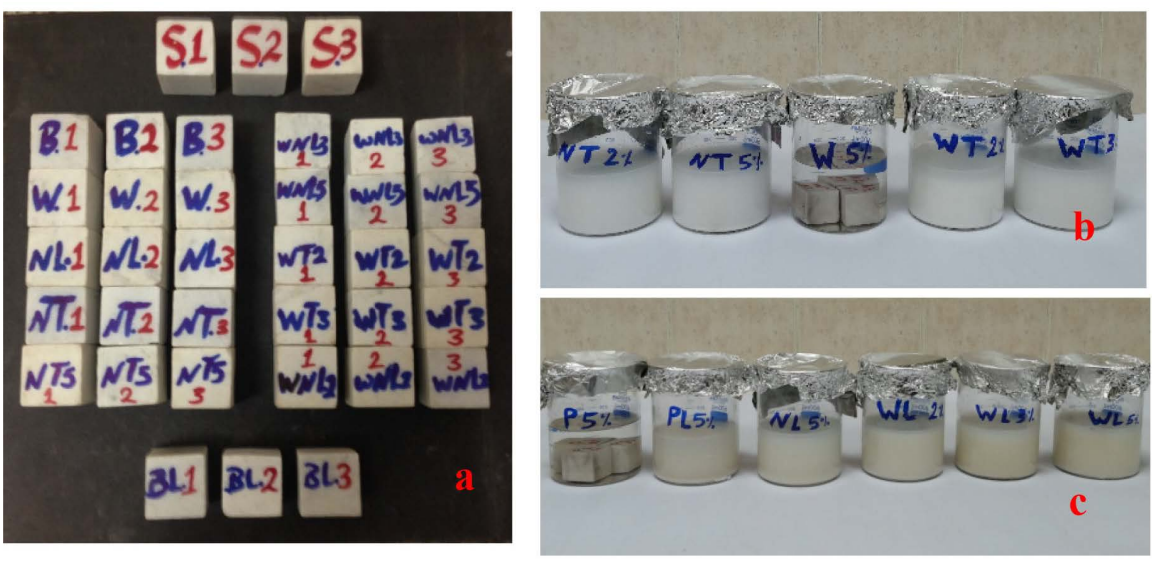

Figure 7. (a) The prepared cubic marble specimens and symbolized, (b) (c) specimens in consolidants.

Table 1. Consolidation materials and nanocomposite materials used in our experimental study.

\begin{tabular}{ccccc}
\hline NO. & Consolidation Materials (Code) & Per. \% & Samples & Solvents \\
\cline { 2 - 4 } 1 & Paraloid B72 or B82 (P) & $2 \%$ & 3 & Acetone \\
2 & Wacker OH 100 (W) & $5 \%$ & 3 & Ethanol \\
3 & Nano Lime (NL) & $5 \%$ & 3 & Alcohol \\
4 & Nano Titanium (NT.2) & $2 \%$ & 3 & Alcohol \\
5 & Nano Titanium (NT.5) & 3 & Alcohol \\
6 & Wacker OH 5\% + Nano Titanium 2\% (W.T 2) & 3 & Ethanol \\
7 & Wacker OH 5\% + Nano Titanium 3\% (W.T 3) & 3 & Ethanol \\
8 & Wacker OH 5\% + Nano Lime 2\% (W.L 2) & 3 & Ethanol \\
9 & Wacker OH 5\% + Nano Lime 3\% (W.L 3) & 3 & Ethanol \\
10 & Wacker OH 5\% + Nano Lime 5\% (W.L 5) & 3 & Ethanol \\
11 & Paraloid B72 2\% + Nano Lime 5\% (P.L 5) & 3 & Acetone \\
12 & Stander samples (S) & 3 & \\
\hline
\end{tabular}

The nanomaterials (nano lime-nano titanium) prepared in laboratory of nanotechnology science institute in Beni-Sauf university, according to international standards and approved by the analytical and examination techniques (XRD, TEM and SEM).

All consolidants prepared in laboratory of national research center for distribution of nano materials by using ultrasonic base and applied in lab of conservation department, faculty of archaeology in Cairo university. I have bought all nanomaterials from institute of nanotechnology in Benisauif university. All nanomaterials particles (nano lime-nano titanium) from $75-50 \mathrm{~nm}$ according to data sheet of any selected materials shown in Figure 8 \& Figure 9.

Consolidants applied with immersion technique for 3 hours and then left to dry off for 3 weeks at room pressure and temperature, to affirm polymerization process of consolidants (Figure 7(b)). 


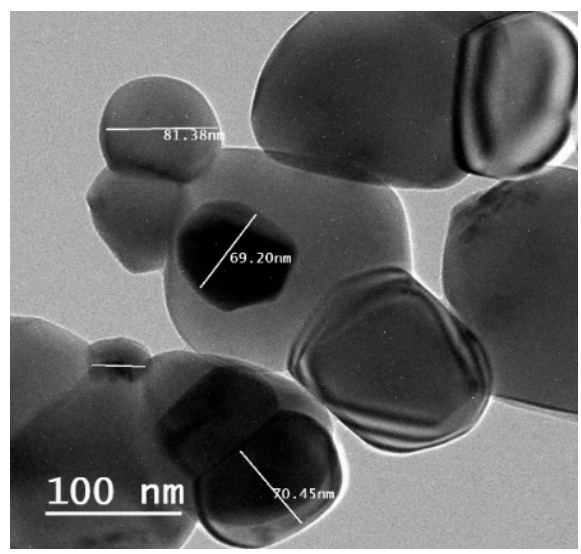

Figure 8. Nano titanium particles under TEM.

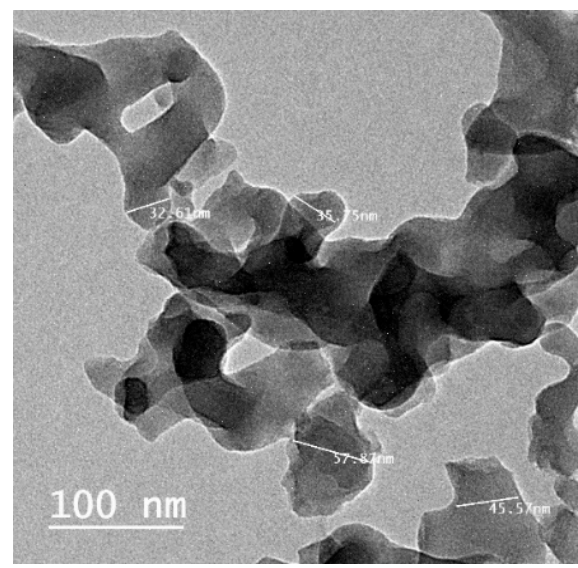

Figure 9. Nano lime particles under TEM.

\subsection{Physical Properties before and after Consolidation}

The physical properties (Bulk density ( $\rho$ ), water absorption (Wa) and apparent porosity (n)) of these samples were determined by calculating the volume of each sample, measuring the dry weight and the wet weight of each sample. The physical properties were calculated as follows.

\subsubsection{Density ( $\rho$, ASTM C97/C97M-15)}

Density is the weight of the oven-dried rock divided by its total volume. It obtained by dividing the dry Mass (after drying for $24 \mathrm{~h}$ at $110^{\circ} \mathrm{C}$ ) of the specimens by the total volume (solids and voids) (Christaras, 1996). $\rho$ in $\mathrm{g} / \mathrm{cm}^{3}$ was determine as follow in Equation (1),

$$
\rho=\frac{M}{V}=\cdots \mathrm{gm} / \mathrm{cm}^{3}
$$

where: $(\rho)$ is the density in $\mathrm{g} / \mathrm{cm}^{3},(M)$ is the Mass in gm and $(V)$ is volume in $\mathrm{cm}^{3}$.

\subsubsection{Apparent Porosity (n, ASTM C97-83)}

Porosity is the ratio of the volume of pore space to the total volume of the sam- 
ple. The porosity of rock and stone helps to determine the strength and durability, but also permits estimates of the content of moisture and flow through the masonry, Equation (2).

$$
(n)=\frac{(M 2-M 1)}{V} \times 100
$$

where $M 1$ is the Mass of the dried specimen, $M 2$ the Mass of the soaked specimen, and $V$ the total volume of the sample.

\subsubsection{Water Absorption (W.a, ASTM C97/C97M-15)}

The weight of water absorbed by the rock after 24 hours of immersion in water divided by its oven-dried weight expressed as a percentage of its oven-dried weight. It was calculated by dividing the absorbed water weight (after a bath of $24 \mathrm{~h}$, in vacuum) by the dry weight of specimens, as shown in Equation (3).

$$
W a=\frac{\left(W_{2}-W_{1}\right)}{W_{1}} \times 100
$$

where: ( $W a)$ is the water absorption in \%, $W_{1}$ and $W_{2}$ is dry and wet weight in gm.

After determination of the physical properties of the treated or consolidated specimens, the result must be recognized through data comparison between before and after consolidation.

The values of density and apparent porosity of consolidated and treated samples refers to the ability of Wacker $\mathrm{OH} 100$ enhanced with nano calcium hydroxide particles (WL-2, WL-3, WL-5) to make positive change and improvement in physical properties of consolidated samples. The density of all sample increased after consolidation process.

The porosity of samples treated with only Wacker $\mathrm{OH} 100$ with concentration $\% 5$ had decreased to low level of porosity after consolidation, in another side, the additives of nano materials like titanium and calcium hydroxide have acceptable changes and successfully. Paraloid B72 has a good level change and decreasing of porosity but very low changes with nano lime additive.

Water absorption of marble samples (W, WL.3, WL.5, WT.3, P) have decreased obviously from $(0.6 \%-0.7 \%)$ on another side nano titanium with concentration (2\% - 5\%) and nano lime 5\% + Paraloid B72 5\% dispersed in acetone showed low decreasing in water absorption degree ranged from $(0.3 \%, 0.4 \%)$ as shown in Figures 10-12.

\subsection{Mechanical Properties, Compressive Strength $(\sigma c)$}

The compressive strength is the maximum load per unit area that the stone can bear without crushing. A higher compressive strength indicates that the stone can withstand a higher crushing load. The required values range from $1800 \mathrm{psi}$ (12.45 MPa) for marble to $19,000 \mathrm{psi}(131 \mathrm{MPa})$ for granite. To determine the compressive strength, at least 5 specimens are tested in ASTM 170. They should be cubes at least 2" to 3 " on each side. Each face must be perfectly flat and they 


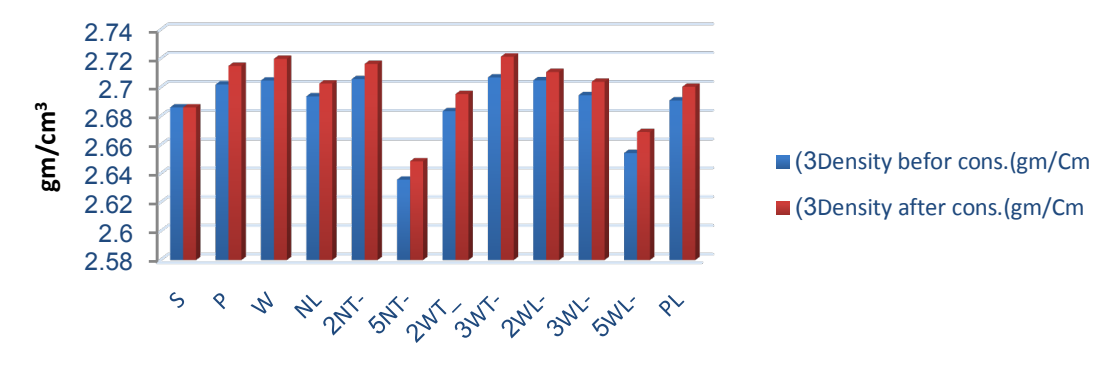

Figure 10. Average of density before and after consolidation processes.

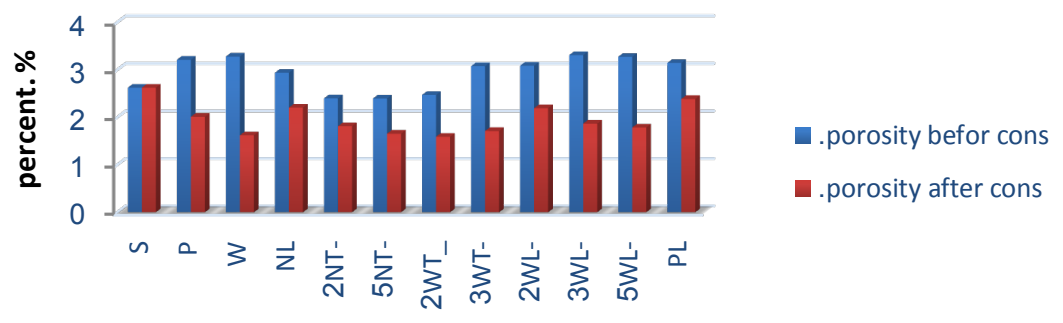

Figure 11. Apparent porosity before and after consolidation processes.

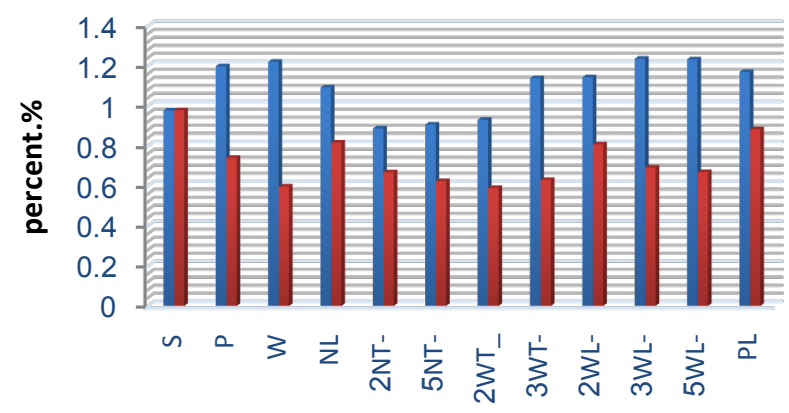

ש.W.A befor cons

口.W.A after cons

Figure 12. Water absorption before and after consolidation process.

must be parallel or perpendicular with each other. Faces must be smooth with no tool marks and there should be no nicks at the corners [23].

The measurement of compressive strength $(\sigma c)$ of the untreated, treated and treated marble samples after artificial aging were carried out using test machine MEGA 10-100-10 Dcompression-testing machine, with the load applied perpendicular to the bedding plane. According to ASTM C 170, to study the efficiency of consolidation materials, 12 cubic marble (Volume $27000 \mathrm{~mm}^{3}$ ) samples have been prepared and tested inside laboratory of National Center for Building Materials \& Housing Research, the average values of compression strength were recorded as summarized in Table 2.

The results indicated that the treatment with Wacker oH100 5\% with nanolime 3\% enhanced mechanical properties (compressive strength and $\mathrm{Vp}$ velocity) 
Table 2. Results of mechanical properties refers to the high compressive strength of treated marble samples (WL.3).

\begin{tabular}{cccccc}
\hline $\begin{array}{c}\text { Sample } \\
\text { Code }\end{array}$ & $\begin{array}{c}\text { L. } \\
\text { mm }\end{array}$ & $\begin{array}{c}\text { W. } \\
\text { mm }\end{array}$ & $\begin{array}{c}\text { Area } \\
\left(\mathrm{mm}^{2}\right)\end{array}$ & $\begin{array}{c}\text { Force (P) } \\
(\mathrm{N})\end{array}$ & $\begin{array}{c}\text { Compressive strength ( } \sigma) \\
\text { N/mm (MPa) }\end{array}$ \\
\hline S3 & 30 & 30 & 900 & 5580 & 6.21 \\
P3 & 31 & 31 & 960 & 6001 & 6.244537 \\
W3 & 30 & 30 & 900 & 5680 & 6.311111 \\
NL.3 & 31 & 31 & 960 & 5750 & 5.989594 \\
NT.2 & 30 & 30 & 900 & 6002 & 6.672667 \\
NT.5 & 29 & 30 & 880 & 6050 & 6.839774 \\
WT.2 & 30 & 30 & 900 & 5821 & 6.474778 \\
WT.3 & 30 & 30 & 900 & 5934 & 6.592444 \\
WL.2 & 31 & 31 & 960 & 5590 & 5.826327 \\
WL.3 & 30 & 30 & 900 & 6502 & 7.224556 \\
WL.5 & 30 & 30 & 900 & 5701 & 6.336 \\
PL.5 & 31 & 31 & 960 & 6082 & 6.330489 \\
\hline
\end{tabular}

of the marble specimens under investigation ( $\sigma \mathrm{c} 7.22 \mathrm{MPa})$ better than other consolidants as shown in Figure 13 and summarized in Table 2.

\subsection{Examination and Analytical Characterization}

Scanning Electron Microscope (SEM) attached with Energy Dispersive X-ray spectroscopy (EDX) and polarizing light microscope have been used to determine the most effective consolidated composite material. The morphology and the chemical constituents of consolidated samples have been investigated very well.

The results of the physical and mechanical tests gave a clear indication of the most effective consolidation materials to be submitted and investigated to show the changes that took place using the above methods. Figure 14 represents the submitted specimens which examined by using SEM with magnification 500x for control sample and treated marble specimens.

In Figure 14, the untreated sample (a) shows many disintegration patterns with micro cracks obviously, (b) treated sample with nano titanium dioxide 5\% shows homogenous and smooth surface of consolidated sample, (e) display the treated sample treated with nano titanium dioxide $2 \%$ characterized with rough and cracked surface, (c) sample treated with nano titanium $2 \%$ dispersed in (Wacker OH 100) 5\% in ethanol shows the distribution of consolidant between grains but not greatly like (f) sample treated with nano titanium $5 \%$ dispersed in (Wacker OH 100) 5\% in ethanol which create a smooth surface with nano titaniumregularly distributed in network of polymer as a coating layer. (d) sample treated with nano lime 5\% dispersed in (Paraloid B 72) 5\% in acetone shows very smooth surface in comparison with sample (e and f). 

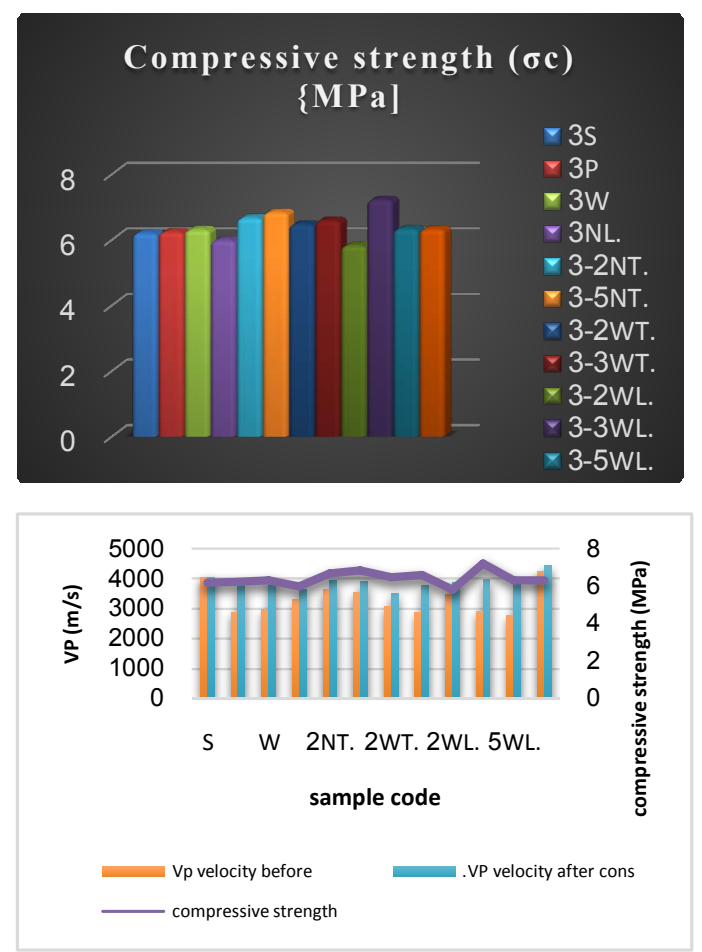

Figure 13. Results of mechanical properties refer to the high compressive strength and higher Vp velocity of treated marble specimen (WL.3).
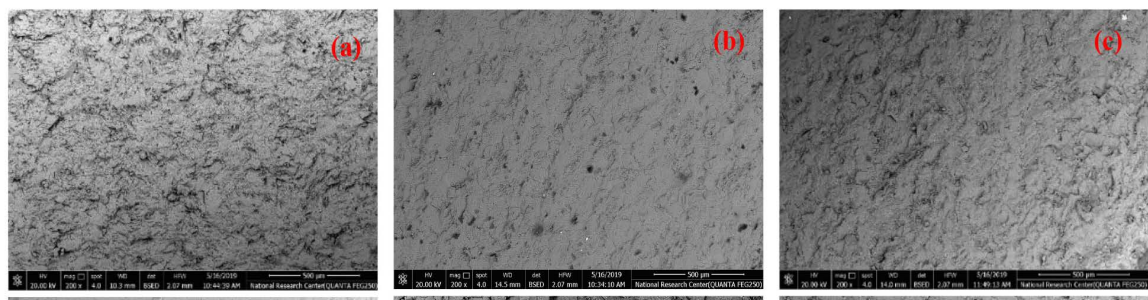

(d)
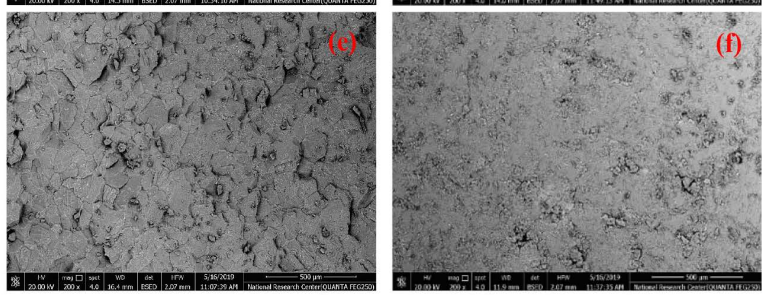

Figure 14. SEM micrographs of best physical and mechanical properties of consolidated marbles specimens.

In Figure 15, the specimen treated with nano lime 3\% dispersed in (Wacker OH 100) $5 \%$ in ethanol (WL.3) has been examined with SEM, PLM and analyzed with EDX device. The micrograph shows the smooth surface of consolidated specimen under 500 um magnification (SEM) and (PLM) micrograph shows the prevalence of consolidant between grains. So, it's submitted to use for consolidation and restoration of the selected area of minbar Soliman pasha mosque after documentation and cleaning processes. 

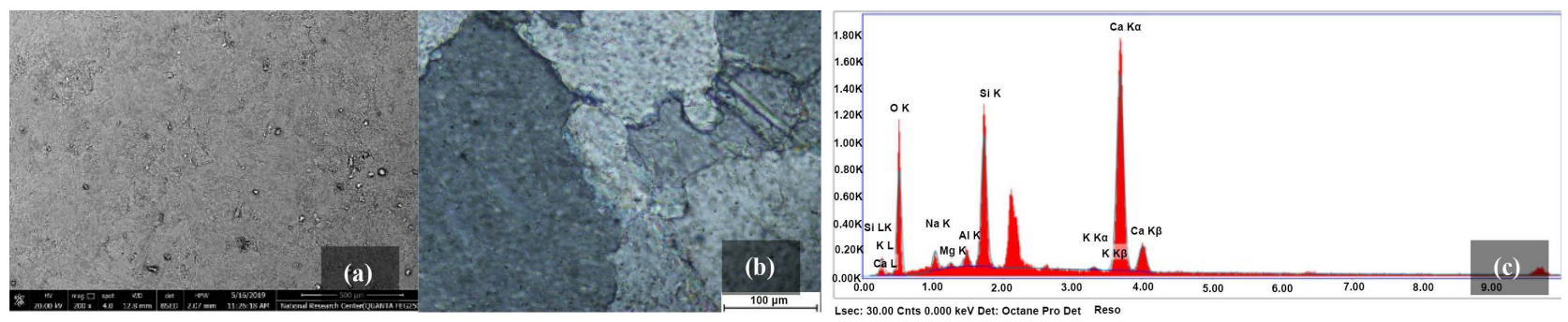

Figure 15. The smooth surface of consolidated sample by SEM-500 um magnification (a), (b) shows the prevalence of consolidant under PLM-Cn and (c) shows the elemental analysis of consolidated surface of marble specimens.

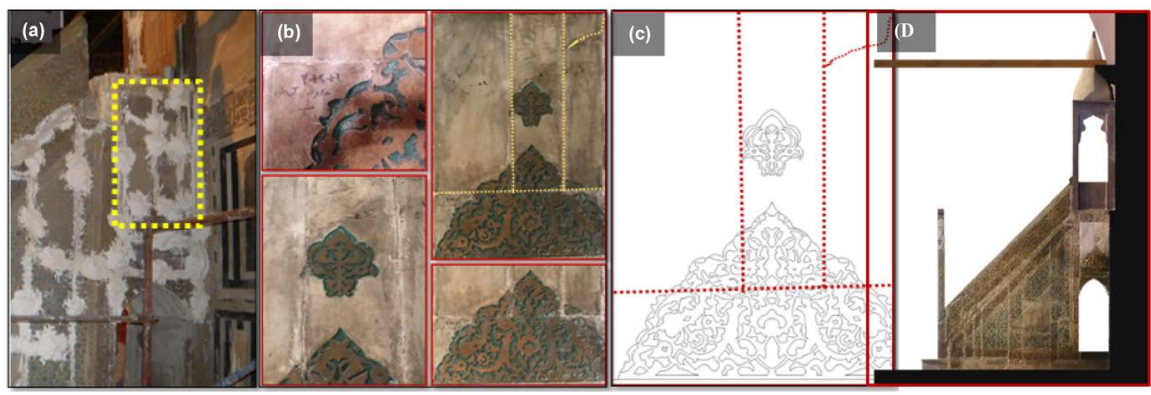

Figure 16. The selected area for applying results of experimental studies for conservation (a) shows this area through fixing project of minbar in 2014 (b) the area now and spots on deterioration aspects, (c) documentation of the area outline by using autocade program to show its content of 4 white decorated marble slabs and (d) shows documented side elevation by using sketch up designing program.

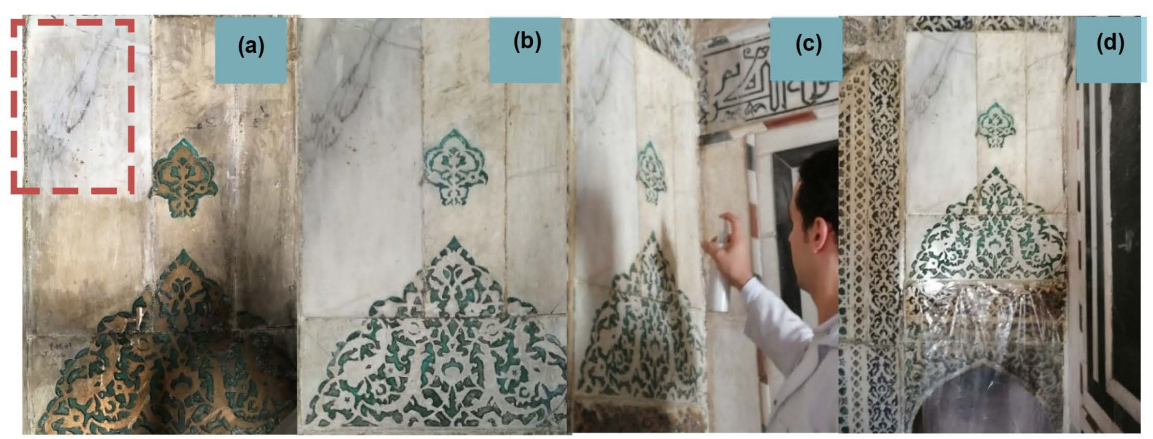

Figure 17. Steps of cleaning processes (a) shows the tested area by mechanical methods after applied chemical cleaning (b) shows selected area after finishing cleaning processes (c) shows the application of consolidant with spray technique and the selected area after applying consolidant in (d).

\section{The Conservation Processes of the Minabr}

In accordance with the decision of the Standing Committee of Islamic Antiquities dated 17/12/2018 to approve the removal of colors and modern gilding with prominent decoration, all gilding decoration removed by mechanical methods. To remove remains of varnish and modern golden paints, chemical solvents mixture prepared from (1/4 Di Methyl Formamide: 1 Acetone: 1 Alcohol) had been used and then all area washed for 3 times with water and alcohol due to removing all remains of previous chemical solvents as shown in Figure 16. 


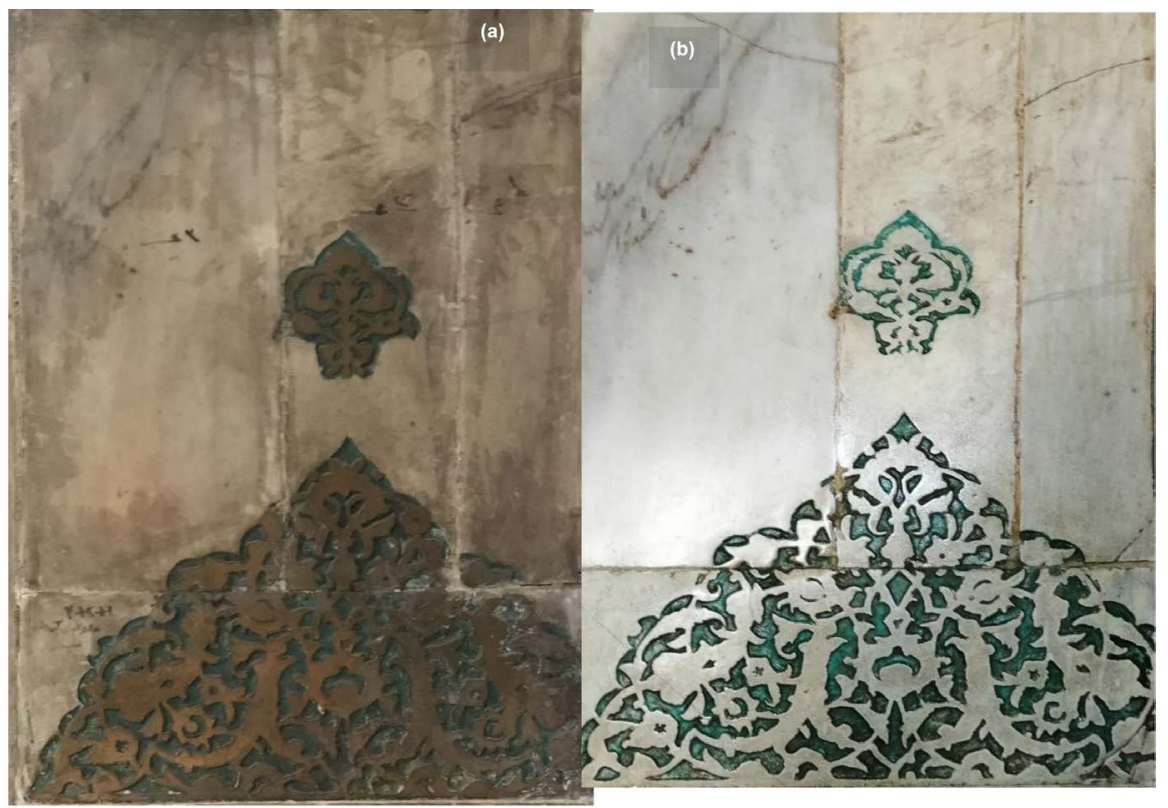

Figure 18. Shows the selected area (Panel) before (a) and after conservation process (b).

Conservation team still working till now in conservation of this minbar to finish the conservation procesees. The selected area (Panel) before and after conservation is presented in Figure 17 and Figure 18.

\section{Conclusions}

In Egypt, there are stone and marble minbars unique from different eras. Unfortunately, they all exposed to different environmental damage factors, but the human factor has a greater role and affective in the damage of these minbars. In this study, we shed light on one of the most important marble minbars from ottoman era, minbar of Suleyman Pasha El-Khadem Mosque (Sariet-Al Gabal) in Salah El-din citadel in Cairo, which was found by examination and analysis of marble Carrara.

To enhance and improve the physical and mechanical properties of the marble samples, eleven consolidants had been used. Some traditional stone strengthener polymers like Wacker OH 100 and Paraloid B 72 had been used for consolidation of marble samples. Some Nano particles and Nano composites of nanomaterials powder like nano titanium dioxide and nano lime also had been used in the experimental study. In addition to its ability to make protective coating surface. After consolidation process physical and mechanical properties showed that Wacker $\mathrm{OH} 100$ alone or with nanomaterials had a remarkable result. The consolidant mixture of nano lime 3\% dispersed in Wacker OH 100 5\% in ethanol (WL.3) showed great enhancement of physical and mechanical properties.

By using SEM coupled with EDX and PLM showed that (WL.3) sample has an excellent distribution of nanomaterials in polymer network between grains, inside micro cracks and formed a protective surface layer. All these results applied 
to a selected area of minbar to be applied to all minbar members.

\section{Conflicts of Interest}

The authors declare no conflicts of interest regarding the publication of this paper.

\section{References}

[1] El-Wehab, H.A. (1946) Tarekh Al masaged Al Atharia. Cairo.

[2] Hamilton, D.L. (1999) Full Manual. Conservation Files: ANTH 605, Conservation of Cultural Resources I. Nautical Archaeology Program, Texas A\&M University, 1-110. http://nautarch.tamu.edu/CRL/conservationmanual

[3] Chiantore, O. and Lazzari, M. (2001) Photo-Oxidative Stability of Paraloid Acrylic Protective Polymers. Polymer, 42, 17-27. https://doi.org/10.1016/S0032-3861(00)00327-X

[4] Wheeler, G. (2008) Alkoxysilanes and the Consolidation of Stone: Where We Are Now. In: Rodrigues, J.D. and Manuel Mimoso, J., Eds., Stone Consolidation in Cultural Heritage: Research and Practice, Proceedings of the International Symposium, Laboratório Nacional De Engenharia Civil, Lisbon, 41-52.

[5] Price, C. (2006) Consolidation. In: Henry, A., Ed., Stone Conservation: Principles and Practice, Donhead, Shaftesbury, 101-126.

[6] Bradley, S.M. (1986) An Introduction to the Use of Silanes in Stone Conservation (4(7)) the Geological Curator.

[7] Helmi, F.M. and Hefni, Y.K. (2012) A Simple Method for Measuring the Static Water Contact Angle for Evaluation the Hydrophobicity of the Consolidating and Protective Materials. 1-12.

[8] Stella, M., Bellusci, M., Fernandez, F. and Persia, F. (2013) Testing of Nanostructured Products for the Protection and Consolidation of Biocalcarenite. Built Heritage 2013-Monitoring Conservation and Management, Milan, 18-20 November 2013, 1454-1460.

[9] Begum, S.N. and Ahmed, F.M.H. (2008) Synthesis of Nanocrystalline $\mathrm{TiO}_{2}$ Thin Films Photocatalytic, by Liquid Phase Deposition Technique and Its Application for Degradation Studies. Journal of Material Science, 31, 43-48. https://doi.org/10.1007/s12034-008-0008-2

[10] Yee, T.K. (2015) Synthesis and Characterization of Titanium Dioxide Nanoparticles in Wood Protection Application.

[11] Hemeda, S., Shoeb, A., Khalil, M. and Abd el Aziz, A. (2018) The Effectiveness of Nano Materials and Nano-Modified Polymers for Preservation of Historic Brick Masonry in Rashid, Egypt. International Journal of Conservation Science, 9, 835-846.

[12] Hemeda, S., Shoeb, A., Khalil, M. and Abd el Aziz, A. (2018) Mechanical Characterization of Nano-Modified Lime-Based Restoration Mortars. Stroitel nye Materialy, 9, 66-74. (In Russian) https://doi.org/10.31659/0585-430X-2018-763-9-66-74

[13] Bozorgmehr, M.A. (2009) Pulpit, Transcendent Symbol of Religious Art Case Study: Qayen Grand Mosque Pulpit. Hamesh Ala Hnr Islamy, 1-27.

[14] Dabbour, L.M. (2012) Geometric Proportions: The Underlying Structure of Design Process for Islamic Geometric Patterns. Frontiers of Architectural Research, 1, 380-391. https://doi.org/10.1016/j.foar.2012.08.005

[15] Christaras, B. (1996) International Congress on the Deterioration and Conservation 
of Stone, Berlin, 1996. 819-829.

[16] Stuart, B.H. (2007) Analytical Techniques in Materials Conservation. Vol. 6, John Wiley \& Sons Ltd., Hoboken. https://doi.org/10.1002/9780470060520

[17] Kempe, D.R.C. and Harvey, A.P. (1983) The Petrology of Archaeological Artefacts. Clarendon Press, Oxford.

[18] Newman, R. (1992) Applications of Petrography and Electron Microprobe Analysis to the Study of Indian Stone Sculpture. Archaeometry, 34, 163-174. https://doi.org/10.1111/j.1475-4754.1992.tb00489.x

[19] Reedy, C.L. (1994) Thin-Section Petrography in Studies of Cultural Material. Journal of the American Institute of Conservation, 33, 115-129. https://doi.org/10.2307/3179421

[20] Hemeda, S., Fahmy, A., Moustafa, A. and Hafez, M. (2019) The Early Basilica Church, El-Ashmonein Archaeological Site, Minia, Egypt: Geo-Environmental Analysis and Engineering Characterization of the Building Materials. Open Journal of Geology, 9, 157-186. https://doi.org/10.4236/ojg.2019.93011

[21] Xu, F., Zeng, W. and Li, D. (2019) Recent Advance in Alkoxysilane-Based Consolidants for Stone. Progress in Organic Coatings, 127, 45-54. https://doi.org/10.1016/j.porgcoat.2018.11.003

[22] Company W. Chemie. (2008) Silres ${ }^{\circledast}$ bs oh 100.

[23] Hemeda, S. (2018) Engineering Failure Analysis and Design of Support System for Ancient Egyptian Monuments in Valley of the Kings, Luxor, Egypt. Geoenvironmental Disasters, 5, Article No. 12. https://doi.org/10.1186/s40677-018-0100-x 